\title{
Proposed parameters of optimal central incisor positioning in orthodontic treatment planning: A systematic review
}

\author{
Linda Sangalli ${ }^{\mathrm{a}, \mathrm{b}}$ (1) \\ Domenico Dalessandri ${ }^{\mathrm{a}}$ \\ Stefano Bonetti $\mathrm{t}^{\mathrm{a}}$ \\ Gualtiero Mandelli ${ }^{\mathrm{a}}$ \\ Luca Visconti ${ }^{\mathrm{a}}$ \\ Fabio Savoldi ${ }^{\mathrm{C}}$ (1)
}

${ }^{a}$ Dental School, Department of Medical and Surgical Specialties, Radiological Sciences and Public Health, University of Brescia, Brescia, Italy

${ }^{b}$ Division of Orofacial Pain, College of Dentistry, University of Kentucky, Lexington, KY, USA

'Orthodontics, Division of Paediatric Dentistry and Orthodontics, Faculty of Dentistry, The University of Hong Kong, Hong Kong SAR

\begin{abstract}
Objective: Planning of incisal position is crucial for optimal orthodontic treatment outcomes due to its consequences on facial esthetics and occlusion. A systematic summary of the proposed parameters is presented. Methods: Studies on Google Scholar ${ }^{\odot}$, PubMed ${ }^{\odot}$, and Cochrane Library, providing quantitative information on optimal central incisor position were included. Results: Upper incisors supero-inferior position (4-5 mm to upper lip, 67-73 $\mathrm{mm}$ to axial plane through pupils), antero-posterior position (3-4 $\mathrm{mm}$ to Nasion-A, 3-6 $\mathrm{mm}$ to A-Pogonion, 9-12 $\mathrm{mm}$ to true vertical line, $5 \mathrm{~mm}$ to A-projection, $9-10 \mathrm{~mm}$ to coronal plane through pupils), bucco-lingual angulation ( $4-7^{\circ}$ to occlusal plane perpendicular on models, $20-22^{\circ}$ to Nasion-A, $57-58^{\circ}$ to upper occlusal plane, $16-20^{\circ}$ to coronal plane through pupils, $108-110^{\circ}$ to anterior-posterior nasal spine), mesio-distal angulation ( $5^{\circ}$ to occlusal plane perpendicular on models). Lower incisors supero-inferior position (41-48 $\mathrm{mm}$ to soft-tissue mandibular plane), antero-posterior position (3-4 $\mathrm{mm}$ to Nasion-B, 1-3 mm to A-Pogonion, $12-15 \mathrm{~mm}$ to true vertical line, $6-8 \mathrm{~mm}$ to coronal plane through pupils), bucco-lingual angulation (1-4 ${ }^{\circ}$ to occlusal plane perpendicular on models, $87-94^{\circ}$ to mandibular plane, $68^{\circ}$ to Frankfurt plane, $22-25^{\circ}$ to Nasion-B, $105^{\circ}$ to occlusal plane, $64^{\circ}$ to lower occlusal plane, $21^{\circ}$ to A-Pogonion), mesiodistal angulation ( $2^{\circ}$ to occlusal plane perpendicular on models). Conclusions: Although these findings can provide clinical guideline, they derive from heterogeneous studies in terms of subject characteristics and reference methods. Therefore, the optimal incisal position remains debatable.
\end{abstract}

[Korean J Orthod 2022;52(1):53-65]

Key words: Esthetics, Incisors, Cephalometrics, Occlusion
Received July 9, 2021; Revised September 9, 2021; Accepted September 29, 2021.

Corresponding author: Fabio Savoldi.

Post-doctoral Fellow, Orthodontics, Faculty of Dentistry, Prince Philip Dental Hospital, 34 Hospital Road, Sai Ying Pun, Hong Kong SAR.

Tel +852-2859-0258 e-mail fabiosavoldi@live.com

How to cite this article: Sangalli L, Dalessandri D, Bonetti S, Mandelli G, Visconti L, Savoldi F. Proposed parameters of optimal central incisor positioning in orthodontic treatment planning: A systematic review. Korean J Orthod 2022;52:53-65.

(C) 2022 The Korean Association of Orthodontists.

This is an Open Access article distributed under the terms of the Creative Commons Attribution Non-Commercial License (http://creativecommons.org/licenses/by-nc/4.0) which permits unrestricted non-commercial use, distribution, and reproduction in any medium, provided the original work is properly cited. 


\section{INTRODUCTION}

Although the concept of facial beauty is abstract, ${ }^{1}$ objective measurements are frequently associated with the perceived facial aesthetics, ${ }^{2}$ and therefore, are complementary to clinical experience for achieving facial harmony at the end of orthodontic treatment. ${ }^{2}$ Orthodontic therapies aim at achieving satisfying aesthetic outcomes, ${ }^{3}$ and should consider the consequences of the treatment on self-esteem ${ }^{4}$ as well as oral health related quality of life of the patient. ${ }^{5}$ Efforts have been made to introduce objective methods to assess ideal proportions of the human face, ${ }^{6,7}$ even if attractive faces may display some asymmetry and proportions that differ from the defined normal values. ${ }^{8}$ Orthodontists must pay particular attention to the position of the incisors in order to organize the dentition in an environment of functional harmony between the hard ${ }^{9}$ and soft tissues, ${ }^{10}$ with an aim of achieving stable long-term treatment results.' While some studies supported an agreement between the perception of orthodontists and patients, ${ }^{11}$ when it comes to facial aesthetics, others showed some differences. ${ }^{12}$ Furthermore, difference in smile aesthetic perception may be present between laypeople of younger and older age. ${ }^{3}$ Nevertheless, some concepts of facial aesthetics are more widely accepted, such as a greater labial inclination of maxillary incisors is generally considered more attractive ${ }^{13}$ by both laypeople and professionals. $^{14}$

The present review selectively analyzed the role of central incisors in orthodontics, as they are probably the most crucial dental elements in terms of aesthetic ${ }^{15}$ and function, ${ }^{16}$ and the control of their position may constitute a challenge during orthodontic treatment. ${ }^{17}$

However, the concept of optimal incisal position is complex. For example, growth influences the relationship between the incisors and the surrounding facial structures and, since females show precocity in skeletal maturation compared to males, ${ }^{18}$ the planning of the incisal position should account for sex-related growth differences. ${ }^{19}$ Independently from growth, aesthetic differences may also be present in incisal position between males and females. ${ }^{20}$ In fact, maximum display of incisors at rest and maximum lip incompetence occurs at 11 -years of age in females and at 12-years in males, ${ }^{21}$ while maximal upper lip thickness is reached by the age of 14 in females and 16 in males. ${ }^{22}$ Males also show a greater mandibular growth than females after the age of 15 years, resulting in increased projection of the chin and relatively more retruded position of the incisors in relation to the facial profile. ${ }^{23}$

Slow and progressive skeletal and soft tissue changes continue after adolescence, eventually producing significant modifications in incisor display with aging. ${ }^{24}$
These include downward and forward nasal projection, tendency of philtrum height to increase at a faster rate than commissure height, thinning of lips, flattening of the smile $\operatorname{arc}^{25}$ and upper vermilion border, ${ }^{26}$ decrease in lower lip elevation, ${ }^{27}$ and drooping of commissures resulting in a reverse resting interlabial curvature. ${ }^{28}$ In particular, the literature has reported an incisal inclination loss with aging. ${ }^{29}$ Such changes highlight the importance of including age-related facial changes in planning the incisal position. ${ }^{24}$ Hence, treatments that diminish lower facial height, reduce lip projection, decrease maxillary incisor display while increasing mandibular incisor display, may promote facial aging over time by worsening upper incisal display. ${ }^{19}$ As a consequence, aesthetic norms are not a static, and those for elderly may be different from norms applicable to younger subjects. ${ }^{30,31}$

Despite the importance of optimal position of central incisors in planning orthodontic treatment, to the best of our knowledge, only one review in the literature has analyzed this topic. ${ }^{26}$ The former study specifically focused on the position of the upper incisor in relation to the lips to achieve an attractive smile. However, no objective measurement of the optimal position of the lower incisors was reported, ${ }^{26}$ and thus, the current literature lacks objective indicators of the optimal position of central incisors.

\section{Objectives}

The objective of the present review was to identify linear (supero-inferior and antero-posterior) and angular (mesio-distal and bucco-lingual) parameters identifying the proposed optimal position of upper and lower central incisors.

\section{MATERIALS AND METHODS}

The present review was registered to PROSPERO (ID: 256903).

\section{Eligibility criteria}

Inclusion criteria were studies in human population, providing quantitative angular and linear information of the optimal position of central incisors.

Animal studies, in-vitro studies, in-silico studies, and those providing only qualitative indications of the optimal position of central incisors were excluded from the review.

\section{Information source}

The database search was conducted in April 2021 by one reviewer (L.S.). First, a historical search was carried out on Google Scholar ${ }^{\circ}$ (to include also records published before 1966). Secondly, a comprehensive search was carried out on MEDLINE via PubMed ${ }^{\odot}$ and on Co- 
chrane Library (to integrate the findings with the most recent evidence). Further records were manually searched from article references and books.

\section{Search strategy}

The historical search was carried out by using the names of the most relevant authors in the field of orthodontics as keywords: "E. H. Angle", "C. H. Tweed", "C. C. Steiner", "W. B. Downs", "R. M. Ricketts", "L. L. Merrifield”, "L. F. Andrews", “J. A. McNamara Jr.", “W. R. Proffit", "G. W. Arnett", and "R. P. McLaughlin", combined with "orthodontic incisors". The performed query was to search, for example: "orthodontics incisors author:EH author:Angle".

The comprehensive search was carried out by using specific terms identifying the data to be extracted as keywords: "incisor(s)", "incisal", "position(s)", "inclination(s)", "angulation(s)", "ideal", "optimal", and "orthodontic (MeSH terms)". The performed query was to search: (((incisor[Title/Abstract]) OR (incisors[Title/Abstract]) OR (incisal[Title/Abstract])) AND ((position[Title/Abstract]) OR (positions[Title/Abstract]) OR (inclination[Title/Abstract]) OR (inclinations[Title/ Abstract]) OR (angulation[Title/Abstract]) OR (angulations[Title/Abstract])) AND ((ideal[Title/Abstract]) OR (optimal[Title/Abstract])) AND ((orthodontics[MeSH
Terms]))).

Both searches included all study types, with no language or time limitations. Subsequently, case reports, literature reviews, and studies published in languages other than English were excluded.

\section{Selection process}

Abstracts of the identified records were independently assessed by two reviewers (L.S., F.S.) to determine whether they met the inclusion criteria. Eligible articles were further analyzed for quality assessment and data collection by one reviewer (L.S.).

\section{Primary outcomes}

Primary outcomes extracted from the articles were linear (supero-inferior and antero-posterior) and angular (mesio-distal and bucco-lingual) parameters, identifying the optimal position of upper and lower central incisors (if quantitative measurements were not present, qualitative findings were included in the discussion section only).

List of abbreviations regarding points, angles and planes are summarized in Supplementary Table 1.

\section{Risk of bias assessment}

A simplified version of the National Institutes of

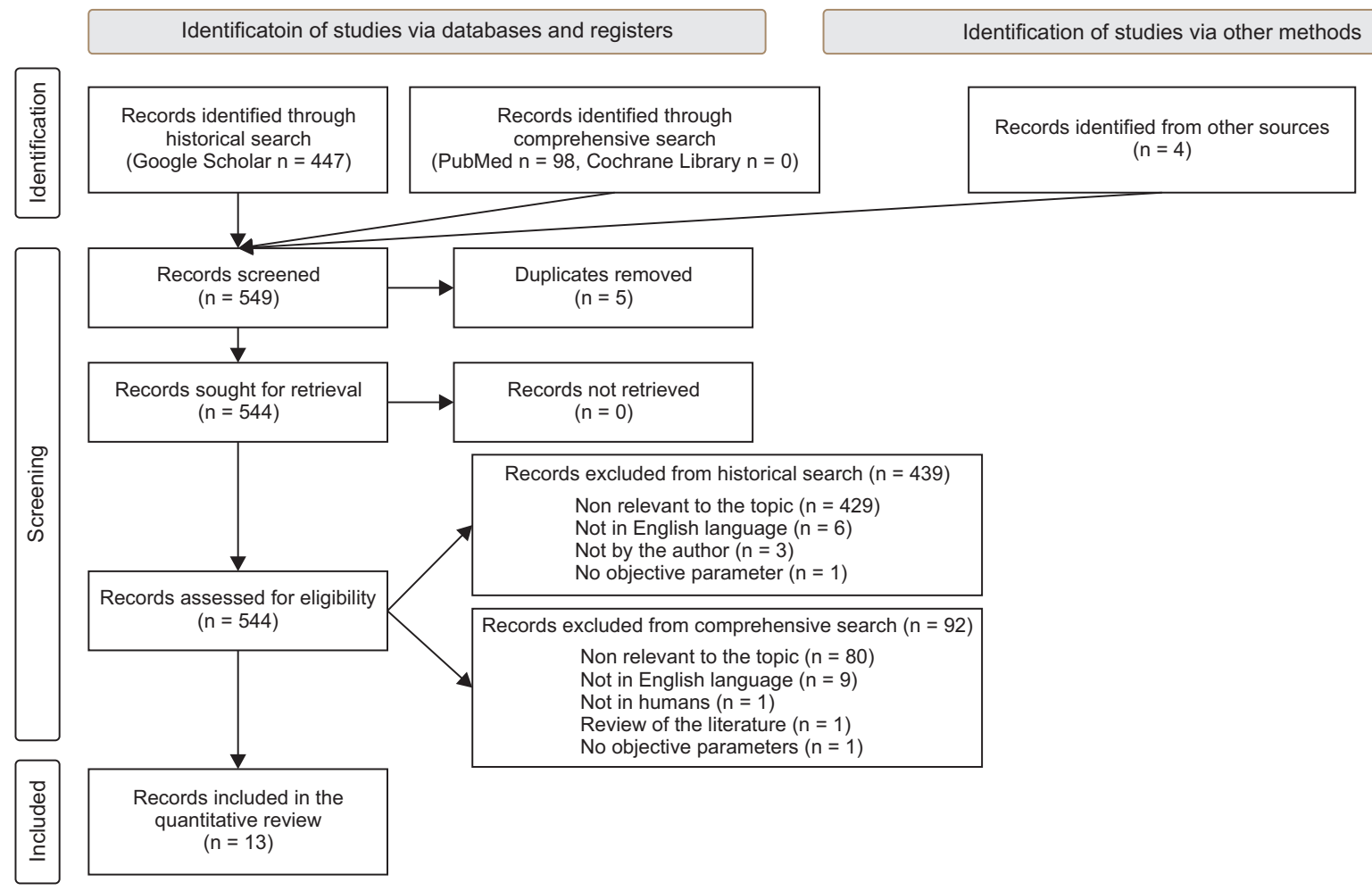

Figure 1. Flow chart illustrating the process of article selection. "not by the author" indicated that the study was not authored by the expected author, but by a homonym author instead. 
Health Quality Assessment Tool for Observational Cohort and Cross-Sectional Studies ${ }^{32}$ was used to assess the risk of bias and the quality of the studies. This qualitative assessment tool comprises eight domains: objectives, population, participation rate, comparison among subjects, sample size calculation, outcomes, blinding, and confounders. Each domain was assessed as "Yes" in case the information was retrieved through the article, or "No" in case of missing data. Out of 8 questions, studies scoring 6 to 8 were considered "Good," those scoring 3 to 5 were considered "Fair," and those scoring 0 to 2 were considered "Poor". Studies with "Poor" rating were excluded.

\section{RESULTS}

\section{Study selection}

Initially, 447 records were identified by the historical search, 98 records by the comprehensive search, and 4 by the manual search, to make a total of 549 records. Then, 5 duplicates were removed, leading to 544 records. Application of the inclusion criteria resulted in the exclusion of 439 records from the historical search and 92 records from the comprehensive search (Supplementary Table 2); none of the 4 manually added records were excluded, leading to 13 eligible articles (Figure 1).

\section{Quality assessment}

None of the articles scored "Poor" in the quality assessment, and all 13 articles were included in the quantitative synthesis (Table 1). Sub-optimal scoring was mostly related to missing report of assessor blinding $(100 \%)$, lack of sample size justification (100\%), and unclear adjustment for confounders (100\%).

\section{Results of individual studies}

Only few parameters were appropriate for a metaanalysis. In addition, studies were heterogeneous in terms of subject characteristics and the resulting evidence was weak; therefore, such quantitative analysis has been reported as additional material (Supplementary Figure 1).

Supplementary data is available at https://doi. org/10.4041/kjod.2022.52.1.53.

\section{DISCUSSION}

The present systematic research only partly permitted to reveal precise quantitative indications of the optimal position of central incisors. Besides the scarcity of studies providing quantitative linear and angular parameters, these were carried out on heterogeneous populations and using variable anatomical references. Furthermore, the lack of functional and aesthetic validation of the

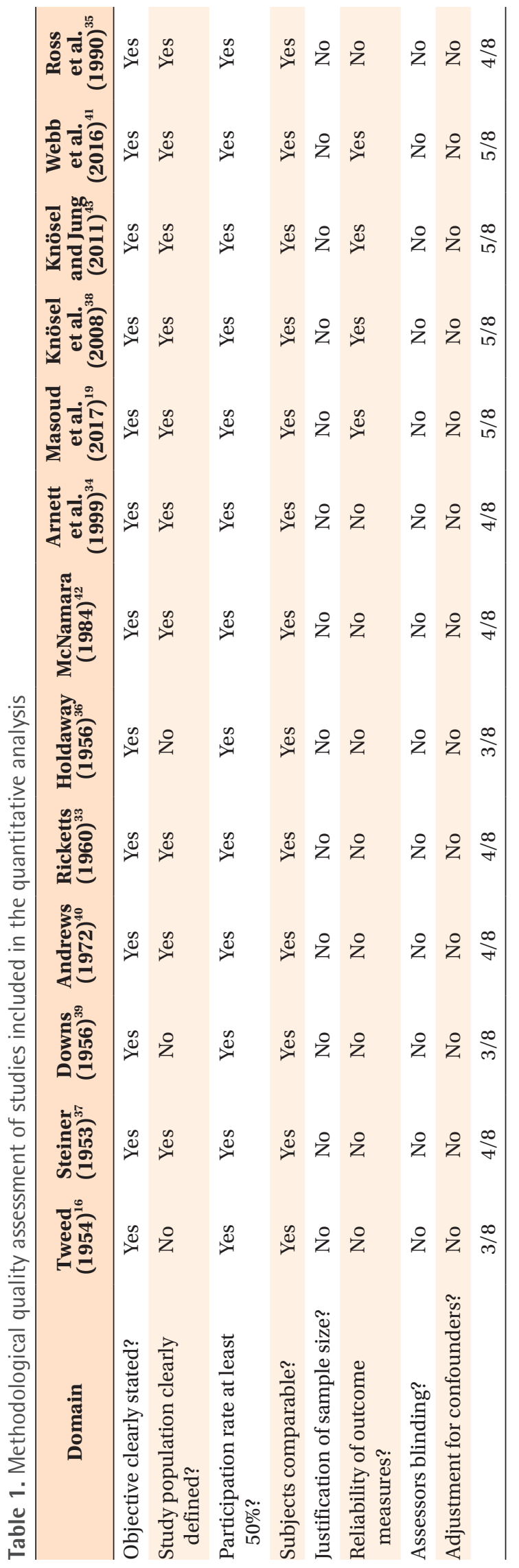


proposed parameters, together with the absence of a long-term clinical assessment, suggests cautious interpretation of the presented findings.

\section{Quantitative results}

Quantitative results of individual studies are presented in Table 2, while qualitative results of articles that were relevant to the topic but not included in Table 2 are presented in the discussion. The 13 studies included in the quantitative analysis included cross-sectional studies and case series.

Overall, the articles showed a heterogeneous population with regard to occlusion and age. Three studies reported findings based on observation of untreated occlusion that was not necessarily ideal, ${ }^{33-35}$ three studies evaluated individuals receiving orthodontic treatment, ${ }^{16,36,37}$ and seven studies involved ideal untreated occlusion..$^{19,38-43}$ The age range was relatively broad. Two studies did not specify the age of the patients, ${ }^{16,36}$ two studies stated the study subjects as adolescents, ${ }^{37,41}$ and two studies described the patients as young adults or adults, but the age range was not otherwise specified. ${ }^{34,42}$ Overall, most of the studies included subjects between 12- and 35-years of age, ${ }^{19,38-40,43}$ while two other studies considered a broader age range of 3- to 44 -years ${ }^{33}$ and 9- to 41 -years. ${ }^{35}$

The list of objective measurements expected to be collected was overjet, overbite, interincisal angle, anteroposterior and supero-inferior position, mesio-distal and bucco-lingual angulation. Although these measurements are necessary to objectively identify the incisal position within the face, different points and axis were used to identify the incisors, ${ }^{16,19,35,38,40}$ and none of the studies provided measurements in all these domains. When the information was provided, the suggested interincisal angle was between $125^{\circ}$ and $135^{\circ} .33,35,37,39$ Only a single study provided a precise indication of overbite, identifying $3 \mathrm{~mm}$ as an optimal value. ${ }^{34}$ The overjet was clarified in two studies, and reported to range between 2 and 3 mm. ${ }^{19,34}$

As for the antero-posterior position, most of the measurements were based on different reference lines for upper (NA, A-Pog, Point A vertical projection, TVL, FFP, FMP, MC) and lower (NB, A-Pog, TVL, MC) incisors, ${ }^{19,33,34,36-39,41,42}$ which limited the comparison among studies. One of the most common parameter evaluated was the distance between the incisors and A-Pog line. The A-Pog line was first adopted by Downs, ${ }^{39}$ who introduced the concept of antero-posterior position of mandible and maxilla in relation to the upper face $e^{39,44}$ and was subsequently utilized by Ricketts ${ }^{33}$ as a reference for the lower incisors, intended as the reciprocal relationship of denture bases to which the incisors should functionally relate. Lastly, McNamara ${ }^{42}$ used A-Pog line to identify the position of hard tissues, which along with soft tissues contribute to aesthetic outcomes. In general, all the authors utilized anatomical references that are related to soft- or hard-tissue structures, except for Arnett, who used TVL, which is related to natural head posture. $^{34}$

Few authors provided indications about supero-inferior measurements ${ }^{19,34}$ suggesting different standards for males and females. ${ }^{19,34}$ For upper incisors, values were at $5 \mathrm{~mm}$ for females and at $4 \mathrm{~mm}$ for males inferior to the upper lip; $;^{34}$ at $73 \mathrm{~mm}$ for males and $67 \mathrm{~mm}$ for females inferior to MA. ${ }^{19}$ Only one study presented the superoinferior position of the lower incisor and suggested to set it at $41 \mathrm{~mm}$ superior to MP for females, and at 48 $\mathrm{mm}$ to MP for males. ${ }^{19}$

Regarding the mesio-distal angulation, the adopted plane was the perpendicular to OP, as proposed by Andrews. ${ }^{40}$ The upper incisors were placed at $5^{\circ}$ to the perpendicular to $\mathrm{OP}^{40}$ and the lower incisors were set at $2^{\circ}$ to it. ${ }^{40}$

Most of the authors recommended bucco-lingual angulation measurements, which were - in some cases specific for males and females. ${ }^{19,34}$ The bucco-lingual angulation was the domain with the greatest heterogeneity of reference lines for upper (MC, OP, upper OP, NA, PNS-ANS, SN) and lower (A-Pog, OP, lower OP, NB, MP, FH) incisors. ${ }^{16,19,33-35,37-40,43}$ Interestingly, when the same reference was adopted, the range was narrow and concordant, especially for the lower incisors with respect to MP. ${ }^{35,38,39,43}$ MP was the most common reference line for lower incisors inclination, and it was first introduced by Tweed ${ }^{16}$ as a reference to which the mandibular incisors should be placed upright to achieve facial harmony, treatment stability and efficient masticatory function. Yet, some authors cast doubts upon this reference plane, due to the its variability with respect to vertical growth type. ${ }^{45} \mathrm{In}$ general, it is noteworthy that the ranges of values were often identified by using one standard deviation (SD) from the mean. However, it is debatable whether one SD, rather than two SD, or other criteria, should be adopted for identifying the range of normality. ${ }^{46}$

\section{Incisal position based on smile}

In the coronal plane, incisal exposure with lips at rest is one of the major aesthetic parameters in orthodontic treatment planning, ${ }^{47,48}$ which is normally considered between 1 and $5 \mathrm{~mm},{ }^{49}$ with intrusion of upper incisors resulting in aging appearance. ${ }^{50}$ ldeally, in adolescents, a minimum of $8 \mathrm{~mm}$ of clinical crown height of upper incisor and a maximum of $2 \mathrm{~mm}$ of gingival exposure should be seen during smiling, ${ }^{51}$ and youthful smiles generally reveal $75 \%$ to $100 \%$ of the upper incisors below the intercommissure line..$^{52}$ Slightly extruded upper 


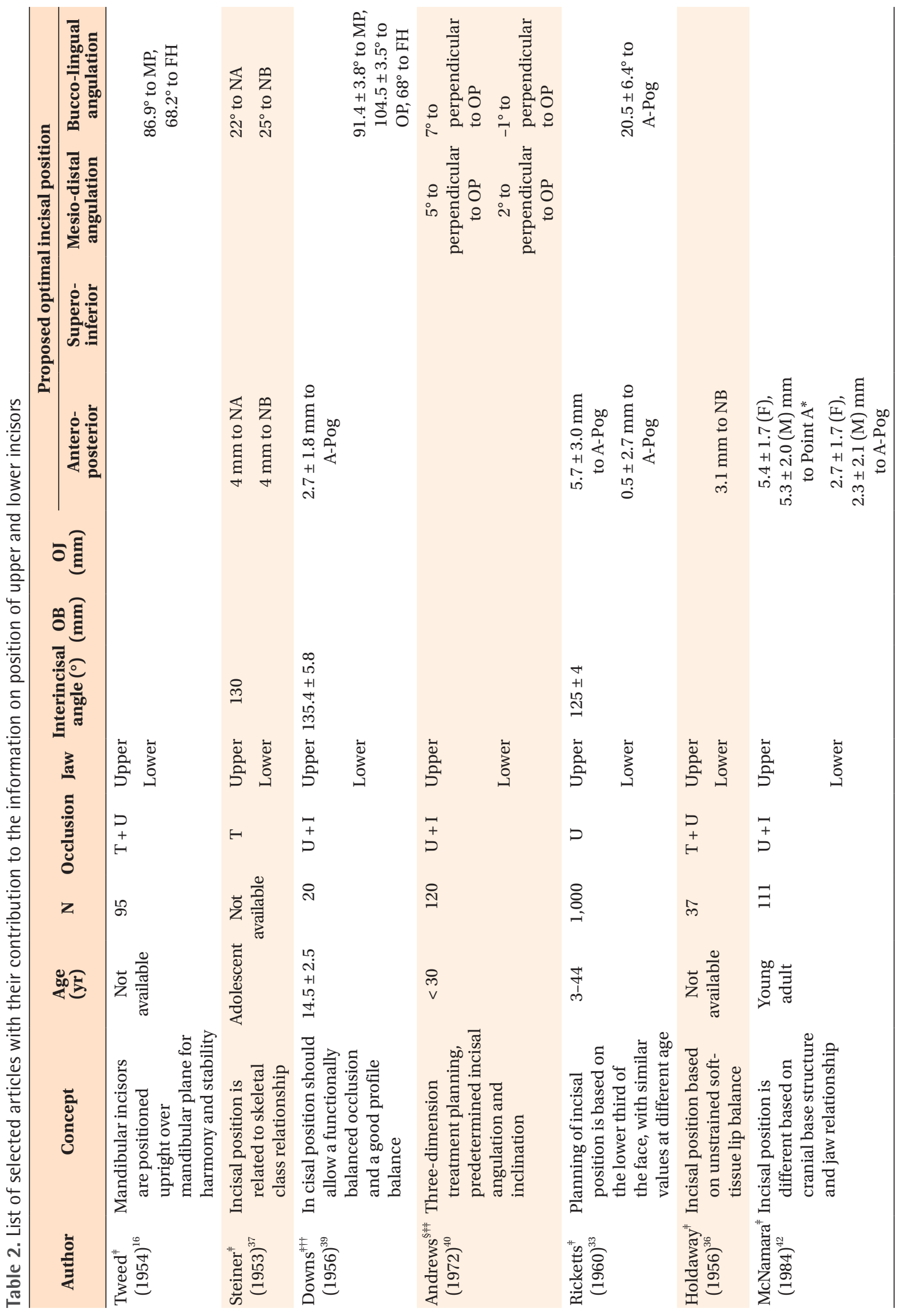




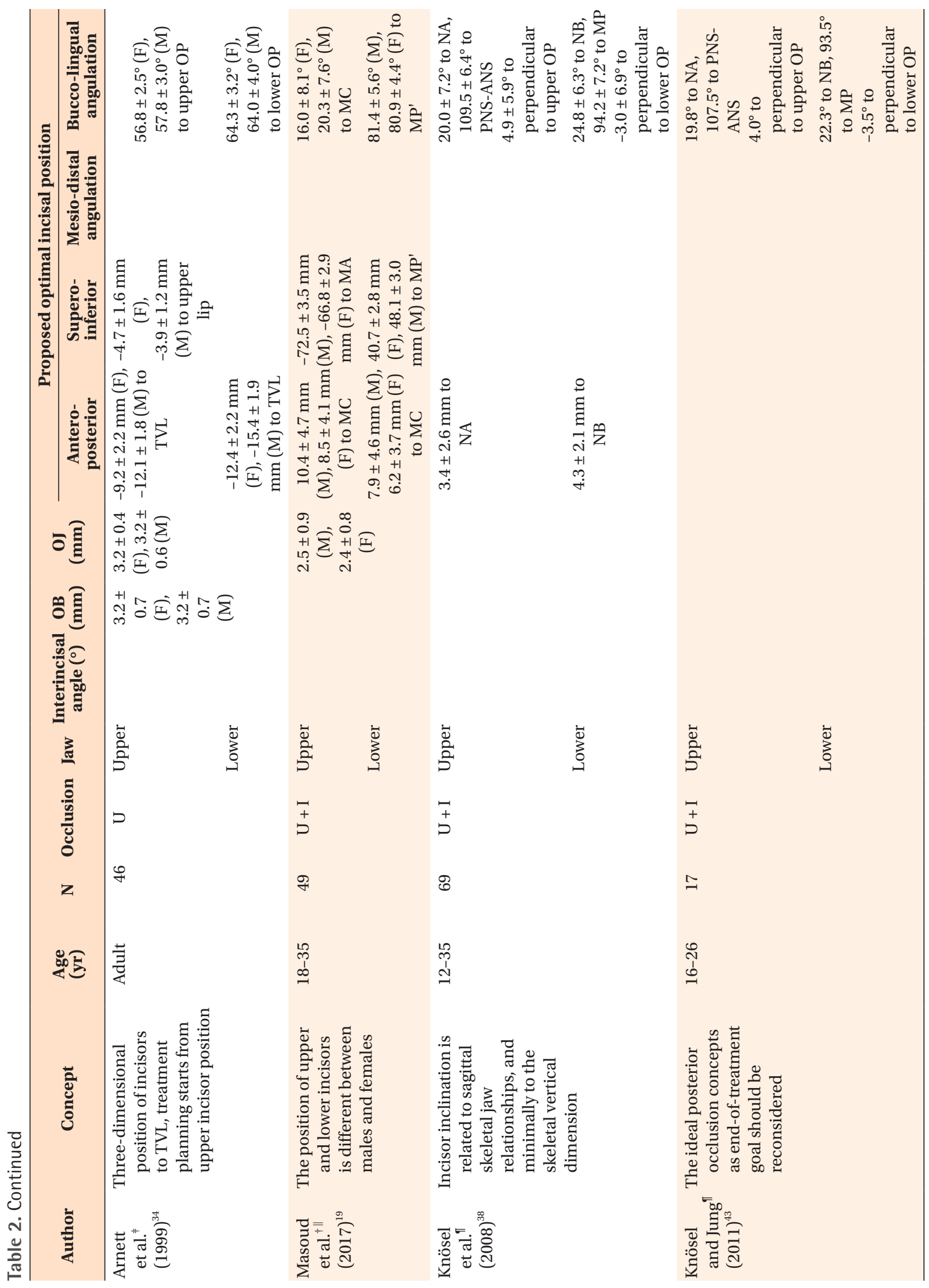




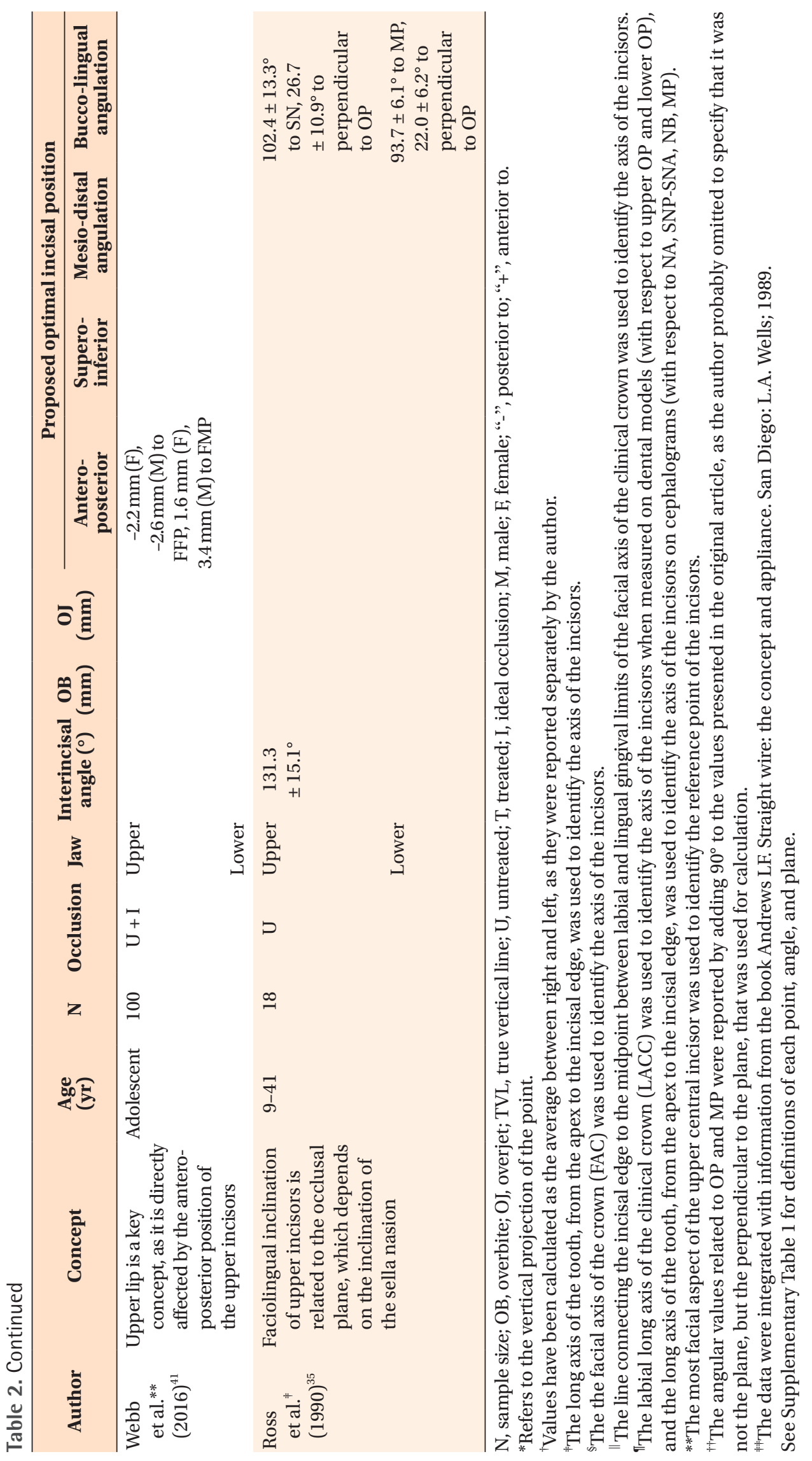


central incisors (with a central-to-lateral incisal step of $1.5 \mathrm{~mm}$ ) are preferred. ${ }^{53} \mathrm{An}$ inadequate incisor display can result from a combination of short clinical crown height, ${ }^{54}$ vertical maxillary deficiency, increased lip thickness, and decreased lip mobility. ${ }^{55}$ The "smile arc" is defined as "consonant" when the maxillary incisal edge curvature runs parallel to the lower lip curvature on smiling, and "non-consonant" when it is flatter. ${ }^{56}$ In the sagittal plane, incisal inclination influences their display, so that proclined maxillary incisors in class 11 division 1 or in class 111 compensation malocclusions have reduced visibility. Conversely, upright or retroclined maxillary incisors such as in class 11 division 2 malocclusion have greater display. ${ }^{57}$

\section{Incisal position based on profile}

The position of incisors can greatly affect the facial profile. $^{57}$ Class 11 division 2 malocclusion induces facial profile flattening, as central incisors are unable to sustain the lips. Conversely, excessive incisal proclination can cause protrusive profile, with mentalis and lip strain on mouth closure, ${ }^{58}$ increased depth of upper labial groove, ${ }^{59}$ unattractive nasolabial angle, and lack of a well-defined labiomental sulcus. ${ }^{25}$ Similarly, a poorly defined labiomental sulcus occurs in mandibular prognathism with retroclined mandibular incisors. ${ }^{58}$ Interestingly, the perception of the anterior limit of the teeth may be not influenced by protrusion of nose and chin. ${ }^{60}$ The preferred profile as per a previous study showed maxillary incisor inclination of $+93^{\circ}$ to $\mathrm{HR}$, and $+7^{\circ}$ to Sn-Pog' and $+7^{\circ}$ to Sn-Pog', while increasing incisor inclination with respect to SN may cause profile aesthetics to deteriorate. ${ }^{61}$

\section{Incisal position based on lips}

Incisors can affect antero-posterior lip position, especially when retraction mechanics are used. ${ }^{62-64}$ The prediction of lip changes with respect to incisal movement varies considerably according to sex, ${ }^{65}$ dentofacial morphology, ${ }^{66}$ and ethnicity. For African Americans, the ratios of upper and lower incisor retraction to upper and lower lip retraction are $1.8: 1$ and $1.2: 1$, respectively. ${ }^{67}$ For Caucasians, the ratios of upper incisor retraction to upper lip retraction varies from $2.2: 1$ to $2.9: 1{ }^{68}$ and the ratios of lower incisor retraction to lower lip retraction ranges from 1.1:1 to $1.2: 1 .^{69}$ Furthermore, an increase of $1 \mathrm{~mm}$ in proclination of upper incisors leads to an increase of $0.42 \mathrm{~mm}$ in prominence of upper lip, 0.35 $\mathrm{mm}$ in depth of upper labial sulcus, and increase of upper lip angle by $1.5^{\circ} .^{70}$ Overall, a positive correlation exists between upper and lower incisor retraction with reduction of lower lip thickness. The lower lip position is affected not only by retraction of lower incisors, but also by upper incisal retraction. ${ }^{70}$ In case of the upper lip, each $3 \mathrm{~mm}$ of retraction of maxillary incisors leads to a thickening of $1 \mathrm{~mm}$ of upper lip. ${ }^{71,72}$ Regarding the vertical position of upper lip in relation to incisors, the lower margin of upper lip should be evenly aligned with the gingival margin of maxillary central incisors. ${ }^{73}$

\section{Incisal position based on gingiva and periodontium}

The position of the incisors can modify the gingival contours and its height when the sulcular attachment apparatus is intact. ${ }^{47}$ For example, it has been shown in a study that the gingival margin and mucogingival junction move in the same direction as the orthodontically extruded lower incisors by $80 \%$ and $53 \%$, of the total amount of dental extrusion, respectively. ${ }^{74}$ During intrusion, the sulcus base and mucogingival junction move apically by $60 \%,{ }^{75}$ while the gingival margin moves apically by $79 \% .{ }^{76}$ In addition, orthodontic extrusion leads to an increase in gingival width and amount of keratinized tissue. ${ }^{74}$ The ideal gingival margins of upper central incisors are at the same level of canines, and the ones of lateral incisors are slightly lower than the adjacent teeth. ${ }^{25}$ Excessive inclination can cause recession of gingival margin, bone dehiscence, and fenestration. ${ }^{77}$ The presence of a thick gingival phenotype is an important factor for minimizing gingival recession at the end of an orthodontic treatment. ${ }^{78}$

\section{Incisal position based on skeletal facial pattern}

The interincisal angle is influenced by both vertical and sagittal skeletal variations. ${ }^{69}$ It is normally between $125^{\circ}$ to $135^{\circ}$ in a mesofacial biotype, ${ }^{79}$ and it varies depending on skeletal facial pattern: the interincisal angle is usually higher for dolichofacial type of faces (with more retroclined lower incisors, placed at $\pm 1 \mathrm{~mm}$ to A-Pog) ${ }^{80}$ and lower for brachyfacial ones (with lower incisors at $+6 \mathrm{~mm}){ }^{81} \mathrm{~A}$ deviation from normal range exposes the treatment to a higher risk of relapse ${ }^{82}$ and worsening of aesthetic perception. ${ }^{83}$ Regarding the sagittal skeletal variation (Class 11 and Class 111), changes in the incisor position tend to follow skeletal malocclusion, with proclined lower incisors associated with a backward mandibular position, and retroclined lower incisors with a forward mandibular position. ${ }^{84}$ As for the upper incisors, skeletal Class 11 was associated with upright maxillary incisors, while skeletal Class 111 was accompanied by labially inclined maxillary incisors. ${ }^{85}$

Interestingly, some studies did not find differences in the interincisal angle with respect to skeletal variations, both vertically and sagittally. ${ }^{81}$

\section{Incisal position based on incisal guide and function}

Incisors play a significant role in cutting of food, production of sounds, ${ }^{86}$ and mandibular guidance. ${ }^{87} \mathrm{ln}$ cisal guidance is defined as the influence of contacting 
surfaces of mandibular and maxillary anterior teeth on mandibular movements, ${ }^{87}$ and is referred to the lingual inclines of the six upper anterior teeth. In presence of well-balanced occlusion, which involves appropriate incisal guidance without any posterior contacts, two thirds of the masseter and temporalis do not contract; therefore, biting force is reduced. ${ }^{88}$ During protrusive sliding movements, incisors and canines act together and anterior teeth disclude in group function. ${ }^{89}$ Conversely, greater forces are generated in presence of posterior contacts during excursive movements, whenever a loss of incisal guidance occurs. ${ }^{88-90}$ Similarly, unfavorable incisal guidance may lead to abnormal condylar movements, potentially contributing to pathologic stress. If incisal guidance is steep, steep cusps, steep occlusal plane, or steep compensatory curve is needed to produce a balanced occlusion. ${ }^{9}$

\section{Long-term treatment stability}

The proposed optimal incisor position should also respond to long-term stability requirement of orthodontic treatment. The teeth should be placed in the center of the alveolar ridge and should be provided with appropriate periodontal support, to avoid the risk of resorption, dehiscence, and gingival recession. ${ }^{91}$ Lower incisors that are either too proclined, especially with a thin gingival phenotype, ${ }^{92}$ or too retroclined, ${ }^{93}$ may be periodontally unstable at long-term. For example, an ANB $<1.45^{\circ}$ with bucco-lingual angulation of the lower incisors or the mandibular plane $<92.6^{\circ}$ may increase the odds of gingival recession by four times..$^{93}$ Likewise, patients with higher values of ANB and Wits presented more adequate gingival thickness and width of keratinized gingiva. ${ }^{78}$ The proposed optimal position of the incisors should also balance the pressure derived from muscles and other soft tissues, in absence of parafunctional habits. ${ }^{94}$

\section{Limitations}

Overall, the topic of the optimal end-of-treatment incisal position is controversial in the orthodontic literature because of the impossibility to objectively formulate standardized norms, due to large inter-individual variability and subjective concepts of aesthetics. This said, a major technical limitation was the adoption of different reference systems for identifying the position of the incisors, which undermined the comparison of the standards proposed by different authors. Further investigations are warranted to achieve a standardization of the recommendations about incisal position. Moreover, the majority of the analyzed articles were limited to Caucasians, and the presented findings may not be generalized to all ethnicities.

\section{CONCLUSION}

This systematic review summarized the quantitative angular and linear indications reported in the published literature with regard to the optimal ranges for upper and lower incisal position. Great heterogeneity was found in terms of subject characteristics and measurement methods, and the majority of the studies were limited to Caucasians. Future research should address the need for standardization of lines and reference points, with studies conducted on larger and appropriately selected samples, including subjects from other ethnicities. Furthermore, studies including objective clinical outcome measurements are needed to investigate the validity of the suggested data.

\section{CONFLICTS OF INTEREST}

No potential conflict of interest relevant to this article was reported.

\section{REFERENCES}

1. Arnett WG, McLaughlin RP. Facial and dental planning for orthodontists and oral surgeons. Edinburgh: Mosby; 2004.

2. Huang YP, Li WR. Correlation between objective and subjective evaluation of profile in bimaxillary protrusion patients after orthodontic treatment. Angle Orthod 2015;85:690-8.

3. Sriphadungporn C, Chamnannidiadha N. Perception of smile esthetics by laypeople of different ages. Prog Orthod 2017;18:8.

4. Johal A, Alyaqoobi 1, Patel R, Cox S. The impact of orthodontic treatment on quality of life and selfesteem in adult patients. Eur J Orthod 2015;37:2337.

5. Zhou Y, Wang Y, Wang X, Volière G, Hu R. The impact of orthodontic treatment on the quality of life a systematic review. BMC Oral Health 2014;14:66.

6. Keele KD. Leonardo da Vinci's elements of the science of man. London: Academic Press; 2014.

7. Ricketts RM. The biologic significance of the divine proportion and Fibonacci series. Am J Orthod 1982;81:351-70.

8. Little AC, Jones BC, DeBruine LM. Facial attractiveness: evolutionary based research. Philos Trans R Soc Lond B Biol Sci 2011;366:1638-59.

9. Mchorris WH. Occlusion with particular emphasis on the functional and parafunctional role of anterior teeth. Part 2. J Clin Orthod 1979;13:684-701.

10. Patil HD, Nehete AB, Gulve ND, Shah KR, Aher SD. Evaluation of upper incisor position and its comparison with lip posture in orthodontically treated 
patients. J Dent Med Sci 2018;17:53-60.

11. Krishnan V, Daniel ST, Lazar D, Asok A. Characterization of posed smile by using visual analog scale, smile arc, buccal corridor measures, and modified smile index. Am J Orthod Dentofacial Orthop 2008;133:515-23.

12. Machado AW, Moon W, Gandini LG Jr. Influence of maxillary incisor edge asymmetries on the perception of smile esthetics among orthodontists and laypersons. Am J Orthod Dentofacial Orthop 2013;143:658-64.

13. Zarif Najafi H, Oshagh M, Khalili MH, Torkan S. Esthetic evaluation of incisor inclination in smiling profiles with respect to mandibular position. Am J Orthod Dentofacial Orthop 2015;148:387-95.

14. Cao L, Zhang K, Bai D, Jing Y, Tian Y, Guo Y. Effect of maxillary incisor labiolingual inclination and anteroposterior position on smiling profile esthetics. Angle Orthod 2011;81:121-9.

15. Tosun H, Kaya B. Effect of maxillary incisors, lower lip, and gingival display relationship on smile attractiveness. Am J Orthod Dentofacial Orthop 2020;157:340-7.

16. Tweed CH. The Frankfort-Mandibular Incisor Angle (FMIA) in orthodontic diagnosis, treatment planning and prognosis. Angle Orthod 1954;24:121-69.

17. Pitts TR. Bracket positioning for smile arc protection. J Clin Orthod 2017;51:142-56.

18. Moore RN, Moyer BA, DuBois LM. Skeletal maturation and craniofacial growth. Am J Orthod Dentofacial Orthop 1990;98:33-40.

19. Masoud Ml, Bansal N, C Castillo J, Manosudprasit A, Allareddy V, Haghi A, et al. 3D dentofacial photogrammetry reference values: a novel approach to orthodontic diagnosis. Eur J Orthod 2017;39:21525.

20. Andrews LF. The diagnostic system: occlusal analysis. Dent Clin North Am 1976;20:671-90.

21. Dickens ST, Sarver DM, Proffit WR. Changes in frontal soft tissue dimensions of the lower face by age and gender. World J Orthod 2002;3:313-20.

22. Mamandras AH. Linear changes of the maxillary and mandibular lips. Am J Orthod Dentofacial Orthop 1988;94:405-10.

23. Sharma P, Arora A, Valiathan A. Age changes of jaws and soft tissue profile. ScientificWorldJournal 2014;2014:301501.

24. Behrents RG. Craniofacial growth series. Growth in the aging craniofacial skeleton. Ann Arbor: University of Michigan; 1985.

25. Sabri R. The eight components of a balanced smile. J Clin Orthod 2005;39:155-67; quiz 154.

26. Dong JK, Jin TH, Cho HW, Oh SC. The esthetics of the smile: a review of some recent studies. Int $\mathrm{J}$
Prosthodont 1999;12:9-19.

27. Chetan P, Tandon P, Singh GK, Nagar A, Prasad $V$, Chugh VK. Dynamics of a smile in different age groups. Angle Orthod 2013;83:90-6.

28. Câmara CA. Aesthetics in orthodontics: six horizontal smile lines. Dental Press J Orthod 2010;15:11831.

29. Devreese H, De Pauw G, Van Maele G, KuijpersJagtman AM, Dermaut L. Stability of upper incisor inclination changes in Class 11 division 2 patients. Eur J Orthod 2007;29:314-20.

30. Wysong A, Kim D, Joseph T, MacFarlane DF, Tang JY, Gladstone HB. Quantifying soft tissue loss in the aging male face using magnetic resonance imaging. Dermatol Surg 2014;40:786-93.

31. Huber KL, Suri L, Taneja P. Eruption disturbances of the maxillary incisors: a literature review. J Clin Pediatr Dent 2008;32:221-30.

32. National Heart, Lung, and Blood Institute. Study quality assessment tools. Quality assessment tool for observational cohort and cross-sectional studies. Bethesda: National Heart, Lung, and Blood Institute; 2013.

33. Ricketts RM. A foundation for cephalometric communication. Am J Orthod 1960;46:330-57.

34. Arnett GW, Jelic JS, Kim J, Cummings DR, Beress A, Worley CM Jr, et al. Soft tissue cephalometric analysis: diagnosis and treatment planning of dentofacial deformity. Am J Orthod Dentofacial Orthop 1999;116:239-53.

35. Ross VA, Isaacson RJ, Germane N, Rubenstein LK. Influence of vertical growth pattern on faciolingual inclinations and treatment mechanics. Am J Orthod Dentofacial Orthop 1990;98:422-9.

36. Holdaway RA. Changes in relationship of points $A$ and $\mathrm{B}$ during orthodontic treatment. Am J Orthod 1956;42:176-93.

37. Steiner CC. Cephalometrics for you and me. Am J Orthod 1953;39:729-55.

38. Knösel M, Engelke W, Attin R, Kubein-Meesenburg D, Sadat-Khonsari R, Gripp-Rudolph L. A method for defining targets in contemporary incisor inclination correction. Eur J Orthod 2008;30:374-80.

39. Downs WB. Analysis of the dentofacial profile. Angle Orthod 1956;26:191-212.

40. Andrews LF. The six keys to normal occlusion. Am J Orthod 1972;62:296-309.

41. Webb MA, Cordray FE, Rossouw PE. Upper-incisor position as a determinant of the ideal soft-tissue profile. J Clin Orthod 2016;50:651-62.

42. McNamara JA Jr. A method of cephalometric evaluation. Am J Orthod 1984;86:449-69.

43. Knösel M, Jung K. On the relevance of "ideal" occlusion concepts for incisor inclination target defi- 
nition. Am J Orthod Dentofacial Orthop 2011;140: 652-9.

44. Savoldi F, Massetti F, Tsoi JKH, Matinlinna JP, Yeung AWK, Tanaka R, et al. Anteroposterior length of the maxillary complex and its relationship with the anterior cranial base: a study on human dry skulls using cone beam computed tomography. Angle Orthod 2021;91:88-97.

45. Zataráin B, Avila J, Moyaho A, Carrasco R, Velasco C. Lower incisor inclination regarding different reference planes. Acta Odontol Latinoam 2016;29:11522.

46. Hixon EH. The norm concept and cephalometrics. Am J Orthod 1956;42:898-906.

47. Moorrees CFA, Kean MR. Natural head position, a basic consideration in the interpretation of cephalometric radiographs. Am J Phys Anthropol 1958; 16:213-34.

48. Machado AW. 10 commandments of smile esthetics. Dental Press J Orthod 2014;19:136-57.

49. Maddalone M, Losi F, Rota E, Baldoni MG. Relationship between the position of the incisors and the thickness of the soft tissues in the upper jaw: cephalometric evaluation. Int J Clin Pediatr Dent 2019;12:391-7.

50. Jeelani W, Fida M, Shaikh A. The maxillary incisor display at rest: analysis of the underlying components. Dental Press J Orthod 2018;23:48-55.

51. Peck S, Peck L, Kataja M. The gingival smile line. Angle Orthod 1992;62:91-100; discussion 101-2.

52. Morley J. The role of cosmetic dentistry in restoring a youthful appearance. J Am Dent Assoc 1999;130:1166-72.

53. Machado AW, McComb RW, Moon W, Gandini LG Jr. Influence of the vertical position of maxillary central incisors on the perception of smile esthetics among orthodontists and laypersons. J Esthet Restor Dent 2013;25:392-401.

54. Sarver DM, Ackerman MB. Dynamic smile visualization and quantification: part 1. Evolution of the concept and dynamic records for smile capture. Am J Orthod Dentofacial Orthop 2003;124:4-12.

55. Spear F. Diagnosing and treatment planning inadequate tooth display. Br Dent J 2016;221:463-72.

56. Sarver DM. The importance of incisor positioning in the esthetic smile: the smile arc. Am J Orthod Dentofacial Orthop 2001;120:98-111.

57. Saver DM. Craniofacial growth series. The importance of incisor positioning in the esthetic smile: the smile arc. Ann Arbor: University of Michigan; 2001. p. 19-54.

58. Bell WH, Jacobs JD, Quejada JG. Simultaneous repositioning of the maxilla, mandible, and chin. Treatment planning and analysis of soft tissues. Am
J Orthod 1986;89:28-50.

59. Ackerman JL, Proffit WR. Soft tissue limitations in orthodontics: treatment planning guidelines. Angle Orthod 1997;67:327-36.

60. Agostino P, Butti AC, Poggio CE, Salvato A. Perception of the maxillary incisor position with respect to the protrusion of nose and chin. Prog Orthod 2007;8:230-9.

61. Ghaleb N, Bouserhal J, Bassil-Nassif N. Aesthetic evaluation of profile incisor inclination. Eur J Orthod 2011;33:228-35.

62. Stromboni Y. Facial aesthetics in orthodontic treatment with and without extractions. Eur J Orthod 1979;1:201-6.

63. Savoldi F, Papoutsi A, Dianiskova S, Dalessandri D, Bonetti S, Tsoi JKH, et al. Resistance to sliding in orthodontics: misconception or method error? A systematic review and a proposal of a test protocol. Korean J Orthod 2018;48:268-80.

64. Savoldi F, Paganelli C. In vitro evaluation of loop design influencing the sliding of orthodontic wires: a preliminary study. J Appl Biomater Funct Mater 2019;17:2280800018787072.

65. Diels RM, Kalra V, DeLoach N Jr, Powers M, Nelson SS. Changes in soft tissue profile of African-Americans following extraction treatment. Angle Orthod 1995;65:285-92.

66. Kusnoto J, Kusnoto $\mathrm{H}$. The effect of anterior tooth retraction on lip position of orthodontically treated adult Indonesians. Am J Orthod Dentofacial Orthop 2001;120:304-7.

67. Caplan MJ, Shivapuja PK. The effect of premolar extractions on the soft-tissue profile in adult African American females. Angle Orthod 1997;67:129-36.

68. Mirabella D, Bacconi S, Gracco A, Lombardo L, Siciliani G. Upper lip changes correlated with maxillary incisor movement in 65 orthodontically treated adult patients. World J Orthod 2008;9:337-48.

69. Jacobs JD. Vertical lip changes from maxillary incisor retraction. Am J Orthod 1978;74:396-404.

70. Kim SJ, Kim KH, Yu HS, Baik HS. Dentoalveolar compensation according to skeletal discrepancy and overjet in skeletal Class 111 patients. Am J Orthod Dentofacial Orthop 2014;145:317-24.

71. UI Huqh MZ, Hassan R, Zainal Abidin S, IA Karobari M, Yaqoob MA. Rickett's and Holdaway analysis following extraction of four premolars and orthodontic treatment in bimaxillary protrusion female Malays. $\mathrm{J}$ Int Oral Health 2020;12:58-65.

72. Oliver BM. The influence of lip thickness and strain on upper lip response to incisor retraction. Am J Orthod 1982;82:141-9.

73. Mackley RJ. An evaluation of smiles before and after orthodontic treatment. Angle Orthod 1993;63:183- 
9; discussion 190.

74. Pikdoken L, Erkan M, Usumez S. Editor's summary, Q \& A, reviewer's critique: gingival response to mandibular incisor extrusion. Am J Orthod Dent Orthop 2009;135:432.e1-432.e6.

75. Murakami T, Yokota S, Takahama Y. Periodontal changes after experimentally induced intrusion of the upper incisors in Macaca fuscata monkeys. Am J Orthod Dentofacial Orthop 1989;95:115-26.

76. Erkan M, Pikdoken L, Usumez S. Gingival response to mandibular incisor intrusion. Am J Orthod Dentofacial Orthop 2007;132:143.e9-13.

77. Dorfman HS. Mucogingival changes resulting from mandibular incisor tooth movement. Am J Orthod 1978;74:286-97.

78. Kalina E, Zadurska M, Sobieska E, Górski B. Relationship between periodontal status of mandibular incisors and selected cephalometric parameters: preliminary results. J Orofac Orthop 2019;80:107-15.

79. Nanda R. Esthetics and biomechnics in orthodontics. 2nd ed. St. Louis: Elsevier; 2015.

80. Gütermann C, Peltomäki T, Markic G, Hänggi M, Schätzle M, Signorelli L, et al. The inclination of mandibular incisors revisited. Angle Orthod 2014;84:109-19.

81. Hernández-Sayago E, Espinar-Escalona E, BarreraMora JM, Ruiz-Navarro MB, Llamas-Carreras JM, Solano-Reina E. Lower incisor position in different malocclusions and facial patterns. Med Oral Patol Oral Cir Bucal 2013;18:e343-50.

82. Simons ME, Joondeph DR. Change in overbite: a ten-year postretention study. Am J Orthod 1973;64: 349-67.

83. Kau CH, Bakos K, Lamani E. Quantifying changes in incisor inclination before and after orthodontic treatment in class 1,11 , and 111 malocclusions. J World Fed Orthod 2020;9:170-4.
84. Ishikawa H, Nakamura S, Iwasaki H, Kitazawa S, Tsukada H, Sato Y. Dentoalveolar compensation related to variations in sagittal jaw relationships. Angle Orthod 1999;69:534-8.

85. Chirivella P, Singaraju GS, Mandava P, Reddy VK, Neravati JK, George SA. Comparison of the effect of labiolingual inclination and anteroposterior position of maxillary incisors on esthetic profile in three different facial patterns. J Orthod Sci 2017;6:1-10.

86. Sackstein M. Display of mandibular and maxillary anterior teeth during smiling and speech: age and sex correlations. Int J Prosthodont 2008;21:149-51.

87. Misch CE. Contemporary implant dentistry. St. Louis: Mosby Elsevier; 2008.

88. Savoldi F, Bonetti S, Dalessandri D, Mandelli G, Paganelli C. Incisal apical root resorption evaluation after low-friction orthodontic treatment using twodimensional radiographic imaging and trigonometric correction. J Clin Diagn Res 2015;9:ZC70-4.

89. Lee RL. Anterior guidance. In: Lundeen HC, Gibbs $\mathrm{CH}$, eds. Advances in occlusion. Boston: John Wright PSG Inc.; 1982. p. 51-79.

90. Misch CE. Dental implant prosthetics. St. Louis: Mosby Elsevier; 2015.

91. Kaley J, Phillips C. Factors related to root resorption in edgewise practice. Angle Orthod 1991;61:125-32.

92. Park JH, Hong JY, Ahn HW, Kim SJ. Correlation between periodontal soft tissue and hard tissue surrounding incisors in skeletal Class 111 patients. Angle Orthod 2018;88:91-9.

93. van der Beek MC, Hoeksma JB, Prahl-Andersen B. Vertical facial growth: a longitudinal study from 7 to 14 years of age. Eur J Orthod 1991;13:202-8.

94. Millett $\mathrm{D}$. The rationale for orthodontic retention: piecing together the jigsaw. Br Dent J 2021;230: 739-49. 